\title{
Factors associated with cattle cleanliness on Norwegian dairy farms
}

\author{
S. J. Hauge,${ }^{*}{ }^{1}$ C. Kielland, $\dagger$ G. Ringdal, ${ }^{*}$ E. Skjerve, $†$ and O. Nafstad ${ }^{\star}$ \\ *Animalia Norwegian Meat and Poultry Research Centre, PO Box 396 Økern, 0513 Oslo, Norway \\ †Norwegian School of Veterinary Science, PO Box 8146 Dep, 0033 Oslo, Norway
}

\section{ABSTRACT}

Animal cleanliness in dairy herds is essential to ensure hygienic milk production, high microbial quality of carcasses, good hide quality, and animal welfare. The objective of this study was to identify on-farm factors associated with dairy cattle cleanliness. The study also examined differences in risk factors and preventive factors between contrasting herds regarding cattle cleanliness. In total, 60 dairy herds, selected from a national database, were visited by 2 trained assessors during the indoor feeding period in February and March 2009. In Norwegian abattoirs, cattle are assessed and categorized according to hide cleanliness, based on national guidelines, using a 3-category scale. Dirty animals result in deductions in payment to farmers. "Dirty" herds ( $\mathrm{n}=$ 30) were defined as those that had most deductions in payment registered due to dirty animals slaughtered in 2007 and 2008. "Clean" herds $(\mathrm{n}=30)$ were those that had similar farm characteristics, but slaughtered only clean animals during 2007 and 2008, and thus had no deductions in payments registered. The dairy farms were located in 4 different areas of Norway. Relevant information, such as housing, bedding, feeding, and management practices concerning cleaning animals and floors, was collected during farm visits. In addition, the cleanliness of each animal over 1 yr of age $(4,991$ animals) was assessed and scored on a 5-point scale, and later changed to a dichotomous variable during statistical analysis. Milk data (milk yield and somatic cell counts) were obtained from the Norwegian Dairy Herd Recording System. Factors associated with dirty animals in all 60 herds were, in ranked order, high air humidity, many dirty animals slaughtered during the previous 2 yr, lack of preslaughter management practices toward cleaning animals, animal type (heifers and bulls/steers), housing (freestalls and pens without bedding), manure consistency, and lack of efforts directed toward cleaning the animals throughout the year. Additional factors associated with dirty animals in the dirty

Received July 29, 2011.

Accepted December 20, 2011.

${ }^{1}$ Corresponding author: sigrun.hauge@animalia.no herds were water leakage from drinking nipples/troughs into lying areas, bedding type, and feed type. In the clean herds, additional risk factors were water leakage from drinking nipples/troughs and low milk yield.

Key words: cow cleanliness, cattle cleanliness, hide cleanliness, dairy cow

\section{INTRODUCTION}

Presentation of clean cattle for slaughter and good slaughter hygiene are fundamental prerequisites for reducing carcass contamination and ensuring food safety in retail products. Fecal material adhering to hides contains enteric bacteria, possibly pathogenic, thus representing a potential source of foodborne disease. Additionally, cattle cleanliness affects hygienic milk production, thermoregulation, health conditions, and hide quality (Reneau et al., 2003; Ruud et al., 2010a). Manure can etch into the skin and cause subclinical infections and irritation (Tancouse, 1986; Nafstad, 1999), an issue of concern for animal welfare.

Hides primarily become soiled by feces, mud, dust, and vegetable matter, caused by the animal's own defecation and animal-to-animal or environment-to-animal contamination. Hughes (2001) suggested that the primary cause of soiling of cattle was diarrhea. Diarrhea or loose manure can be caused by diseases or infections and may result from feeding rations with excess protein and insufficient fiber content.

Regulation (EC) No 853/2004 (European Union, 2004a) states that animals presented for slaughter must be clean. In the UK, the Meat Hygiene Service Clean Livestock Policy includes categorizing cattle according to visual cleanliness when animals are presented at abattoirs, and results in extensively dirty animals being rejected for slaughter (Lowman et al., 1997; Food Standards Agency, 2004). Ireland, Sweden, and Finland have also implemented formal regulations regarding visual cleanliness (Ridell and Korkeala, 1993; Swedish Board of Agriculture, 1998; Doherty, 1999). The Norwegian meat industry has developed national guidelines, based on EC 852/2004 (European Union, 2004b), in which cattle representing a higher risk due to fecal contamination are directed into separate streams for 
meat processing, including heat treatment of the meat products and restricted product applications. Additionally, economic incentives are used to encourage farmers to reduce the number of dirty animals presented for slaughter. A cleanliness categorization of cattle was introduced in Norway in 2000 (Animalia, 2007) and includes 3 categories: category $0=$ clean, category $1=$ moderately dirty at critical locations where contamination can easily be transferred from hide to carcass when opening the hide (contamination on $20-40 \%$ of areas on legs and thighs, up to $50 \%$ of mid-line cut on abdomen and brisket), and category $2=$ very dirty $(>50 \%$ of mid-line on abdomen or $>40 \%$ of thighs and legs). Payment deductions of approximately 5 and $10 \%$ of the carcass value for animals are implemented in categories 1 and 2 , respectively.

About $25 \%$ of Norwegian farmers deliver cattle for slaughter that are categorized as dirty (category 1 or 2 ), representing 4 to $5 \%$ of the cattle slaughtered annually in Norway (Animalia, 2011a). Large seasonal variations exist in categorization, with the proportion of dirty cattle presented for slaughter peaking during the indoor feeding period during the winter months (November to March). Farmers with animal cleanliness problems in their herds need effective and helpful advice for improving the situation. Actions for reducing pathogens at the herd level are not effective (NSCFS, 2010), and thus, the most effective food safety measure is to decrease the number of dirty cattle presented for slaughter. Identification of risk factors for dirty animals is therefore essential to develop effective preventive onfarm strategies for animal cleanliness.

Animal cleanliness on-farm is affected by a range of factors (Herlin, 1997; Lowman et al., 1997; Davies et al., 2000) in the following areas: (1) physical and environmental conditions; (2) management; (3) feeding; and (4) health and production. Management factors include routines for muck scraping, use of bedding material, frequency of supplying new bedding, clipping, washing, brushing, and so on. These factors can themselves be important, and good routines may partly compensate for other negative environmental effects.

Several studies have found that dirty animals (as explanatory variables) are risk factors for compromised health and production issues, such as mastitis, high SCC in milk, and lameness (Cook, 2002; Breen et al., 2009). However, few studies have focused on identifying those factors associated with dirty animals, with dirty animals as the response variable. The effects of stall design, floor types, neck-rail positions, and other mechanical installations on cattle dirtiness have been investigated (Fregonesi et al., 2009; Ruud et al., 2010a,b), and studies have evaluated systems for assessing cow cleanliness (Chiappini et al., 1994; Reneau et al., 2005; Barbari and Ferrari, 2006). However, the effects of management, feeding, and human factors on cattle cleanliness have been the subject of few studies. The meat industry uses economic incentives to encourage the production of cleaner animals for slaughter, but the knowledge-based advisory services for guiding farmers when they have problems with dirty slaughter animals are limited. The objective of this study was to identify on-farm factors associated with cattle cleanliness in dairy herds and to examine differences between contrasting herds regarding dirty and clean cattle presented for slaughter.

\section{MATERIALS AND METHODS}

\section{Study Population}

Sixty dairy herds were included in the study. Herds were selected to obtain 2 contrasting herd groups, designated as "clean" and "dirty" herds that produced clean and dirty cattle at slaughter, respectively. The group designated "dirty" consisted of herds $(\mathrm{n}=30)$ with the most deductions in carcass price due to dirty animals presented for slaughter in 2007 and 2008 (minimum of 2 animals in cleanliness category 2 and 2 animals in category 1 each year), as described in the Carcass Register, a national database in which all animals slaughtered in Norwegian abattoirs are recorded (Animalia, 2011b). The herds designated as "clean" $(\mathrm{n}=30)$ had similar farm characteristics as the dirty herds but none of the animals slaughtered in 2007 and 2008 were categorized as dirty. Inclusion criteria for both herd groups were 4 geographic locations in Norway (Østfold, Oppland, Rogaland, and Trøndelag); at least 15 animals slaughtered annually; milk production on farm; minimum 10 cow-years per herd (defined as total feeding days for cows divided by 365); membership of the Norwegian Dairy Herd Recording System (NDHRS); and same dairy breed. In each region, approximately the same number of animals was slaughtered annually per herd in both clean and dirty herds. Farmers were invited by letter to participate in the study, with letters sent out until 30 positive responses had been received for each group. The letter did not say why they were selected. In total, 113 letters were sent inviting participation.

\section{Data Sampling}

Online Questionnaire to Advisors. In a preliminary study, a questionnaire was sent online to 396 Norwegian herd advisors working in the dairy and slaughter industries. The questionnaire was multiplechoice, in which the advisors could choose more than one alternative and additional free-text options were 
provided. The 6 questions were (1) What do you think is the main problem in cattle herds with many very dirty animals? (12 choices and free-text); (2) Are there differences between production systems? (yes/no/ don't know); (3) If yes, which production system has the most dirty animals? (6 choices + free-text); (4) Do farmers try to reduce the dirtiness of animals? (yes often/no rarely/don't know); (5) If yes, what efforts do they make to achieve this? ( 8 choices + free-text); (6) What advice would you give to farmers with many dirty animals? (free-text). The response rate was $23 \%$ $(\mathrm{n}=91)$. To the first question, the advisors answered that the main problem was due to (in ranked order) the farmer's herdsmanship and management, insufficient or inappropriate bedding material, floor type, and stall design. The advisors considered that differences existed in cleanliness between housing types and animal types, and that young bulls in small pens were the dirtiest animals. Dairy cows in tiestalls or freestalls were considered cleaner than heifers and bulls/steers. Regarding the advisors' opinions on how frequently farmers directed extra efforts toward cleaning the animals, $37 \%$ believed this to be "yes often," whereas $52 \%$ of advisors believed that this happens "no rarely," and $11 \%$ answered "don't know." The most common cleaning effort reported was clipping, including tail trimming, followed by brushing, washing, and scraping the animals. The advisors' suggestions for improving hide cleanliness included correct feeding to prevent loose manure, optimal animal density in pens, use of more bedding material, larger gaps in slatted floors, spending more time in the barn brushing and clipping, various ways to tie the animals up during cleaning (e.g., fixation box), and soap wash with lukewarm water. Women working on-farm was also mentioned as being beneficial for animal cleanliness. Based on the answers received, a questionnaire was later prepared for the farmers to complete during the herd visits.

Herd Visits. This field study was conducted during the indoor feeding period in February and March 2009, when the animals are usually dirtiest. The weather was cold throughout the study period, with snow, and outdoor temperatures ranged between $-5^{\circ} \mathrm{C}$ and $-15^{\circ} \mathrm{C}$. Each farm was visited once by 1 of 2 trained assessors. The assessors visited 2 farms together at the beginning of the study to ensure that the assessment of scores was similar for the 2 assessors. During the farm visit, the questionnaire was completed by the farmer, mediated by the assessor. In total, 56 factors were examined, of which the 19 most important factors are detailed in Table 1 . The variables investigated were as follows:

(1) Animal cleanliness. Each cow, heifer, bull, or steer over 1 yr of age was scored for cleanliness after visual inspection by the assessor. A 5 -point scale was used according to methods utilized by Reneau et al. (2005) and Barbari and Ferrari (2006). The animals were compared with model animals in photographs and scored according to the following categories: $1=$ clean; $2=$ small spots of dirt; $3=$ moderately dirty; $4=$ mostly covered in dirt on legs and belly; $5=$ very dirty, with caked-on dirt. Before statistical analysis, the cleanliness score was transformed to a dichotomous variable where 1 and 2 were clean and 3,4 , and 5 were dirty.

(2) Manure scores. Manure on all the floors was scored on consistency, based on a 5-category scale according to Hulsen (2005). The manure score reflecting digestion also had a 5 -point scale (Table 1).

(3) Management and environmental factors. The farmers were asked an open question about which actions were conducted to improve or maintain the cleanliness of cows, heifers, and bulls/steers, regularly or just before sending to slaughter. Air humidity was judged subjectively using a 3 -grade scale (low, medium, high). Other management factors investigated were frequency of manure removal from floors, bedding management, and feeding regimen (Table 1).

Variables that were recorded in the herd questionnaire but not used in the statistical analyses were environmental factors (e.g., insulation, tiestall design, cow trainers, year of construction, area per animal, type of floor, ventilation type, feed barrier type, type of manure scraping, and indoor/outdoor temperature) and management factors (e.g., organic/traditional production, cooperative enterprises, calving season, whether dairy production is the main income, and the farmer's age).

Database Information. The following data were obtained from the NDHRS database from the year 2009: herd size (number of cow-years), milk yield per cow-year, and individual SCC in milk. These continuous variables were categorized into ordinal groups for statistical analyses (Table 1).

\section{Statistical Analyses}

Data from farm visit questionnaires and the on-farm assessment of cleanliness and manure were coded and a database established in Excel for Windows (Microsoft Corp., Redmond, WA). Further statistical analyses were undertaken using Stata IC for Windows (version 11, StataCorp, College Station, TX). Several continuous variables were transformed into categories, as detailed in Table 1. Linearity between the outcome and 
Table 1. The distribution of the predictor variables in the field study of risk factors for dirty animals ${ }^{1}$

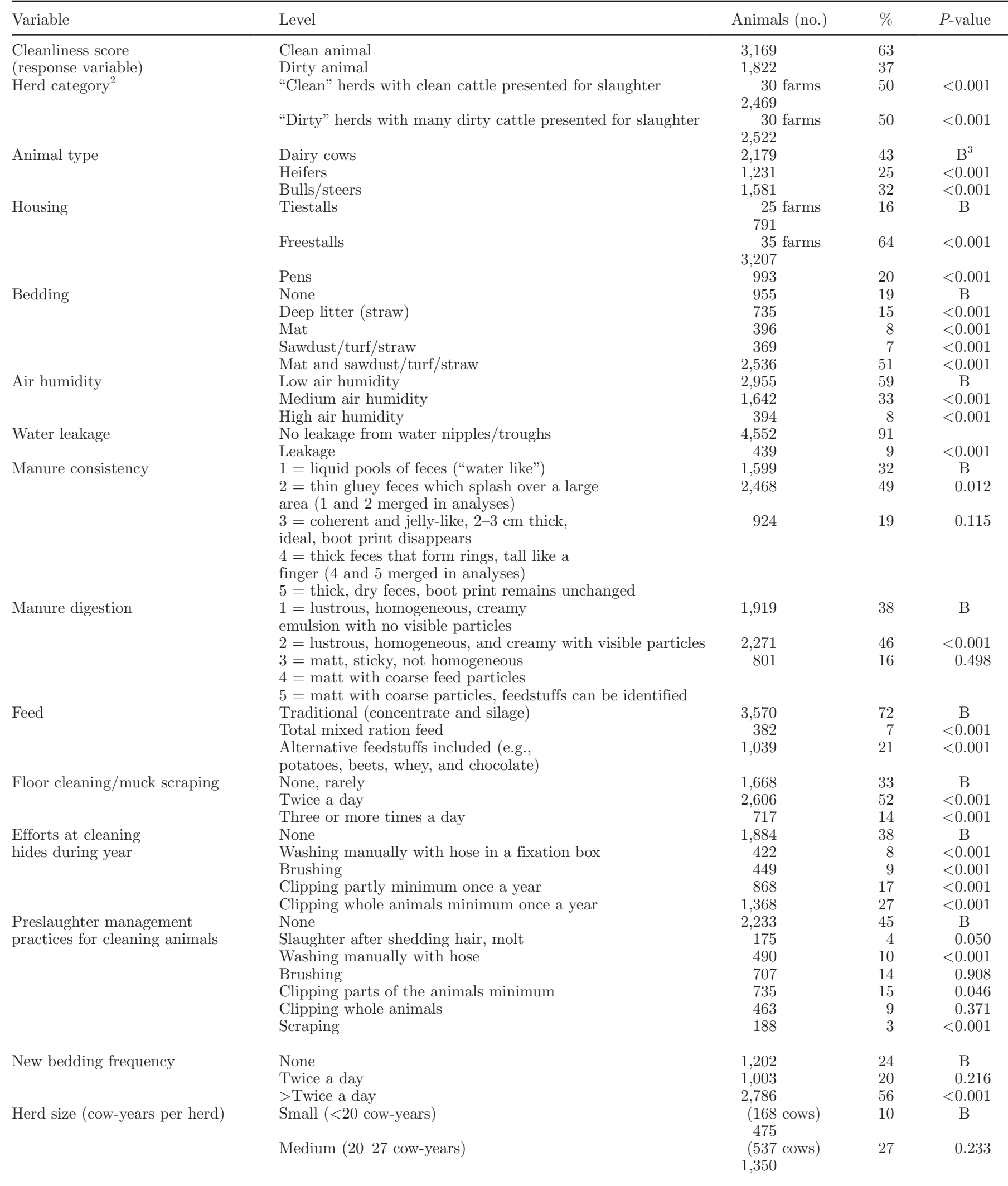


Table 1 (Continued). The distribution of the predictor variables in the field study of risk factors for dirty animals ${ }^{1}$

\begin{tabular}{|c|c|c|c|c|}
\hline Variable & Level & Animals (no.) & $\%$ & $P$-value \\
\hline & Very large ( $>50$ cow-years) & $\begin{array}{l}(746 \text { cows }) \\
1,611\end{array}$ & 32 & 0.603 \\
\hline \multirow[t]{3}{*}{ Milk yield } & Very low $(<6,000 \mathrm{~kg} /$ cow per year $)$ & $\begin{array}{l}(390 \text { cows }) \\
758\end{array}$ & 15 & $\mathrm{~B}$ \\
\hline & Low $(6,000-6,999 \mathrm{~kg} /$ cow per year $)$ & $\begin{array}{l}(506 \text { cows }) \\
1,203\end{array}$ & 24 & 0.316 \\
\hline & High $(>8,000 \mathrm{~kg} /$ cow per year $)$ & $\begin{array}{l}(558 \text { cows }) \\
1,097\end{array}$ & 22 & $<0.001$ \\
\hline \multirow[t]{2}{*}{ Cell count in milk } & High $(>200,000$ cells $/ \mathrm{mL})$ & $\begin{array}{l}(779 \text { cows }) \\
1,804\end{array}$ & 36 & $\mathrm{~B}$ \\
\hline & Medium $(100,000-200,000$ cells $/ \mathrm{mL})$ & & 40 & 0.003 \\
\hline \multirow{3}{*}{ Regions } & Oppland & $\begin{array}{l}20 \text { farms } \\
1,774\end{array}$ & 36 & $<0.001$ \\
\hline & Rogaland & $\begin{array}{l}7 \text { farms } \\
884\end{array}$ & 18 & $<0.001$ \\
\hline & Trøndelag & $\begin{array}{l}19 \text { farms } \\
1,366\end{array}$ & 27 & $<0.001$ \\
\hline
\end{tabular}

${ }^{1}$ The outcome variable was clean (0) or dirty (1) animals. In total, the study included 56 predictor variables, but only 18 predictors listed in this table had an unconditional association with the outcome at a very liberal $P$-value $(P<0.20)$. These variables were used in the logistic model building.

${ }^{2}$ Dirty herds $(\mathrm{n}=30)$ were defined as those that had most deductions in payment registered due to dirty animals slaughtered in 2007 and 2008. Clean herds $(\mathrm{n}=30)$ were those that had similar farm characteristics, but slaughtered only clean animals during 2007 and 2008 , and thus had no deductions in payments registered.

${ }^{3} \mathrm{~B}=$ assigned as baselines for categorical variables.

the dichotomous predictor was investigated graphically. Continuous variables that did not have a linear relationship with the response variable, or that were not normally distributed, were transformed into categorized variables according to their 10th and 90th percentiles, or quartiles.

For comparisons of clean and dirty herds, $t$-tests and ANOVA were used for normally distributed data, and Kruskal-Wallis tests for nonparametric data. In the Results section, $P$-values are reported only for those groups that were found to be significantly different from each other. Initially, when building the model, unconditional association between the dichotomous cleanliness score as the response variable and each of the predictors was examined using simple logistic regression. Variables with a $P$-value $<0.20$ (Dohoo et al., 2009) within this analysis were then considered in the full model, using multivariable logistic regression. Three independent models were made; one for all herds, one for the 30 dirty herds, and one for the 30 clean herds. When building the full model, a forward stepwise technique was used, starting with the variables with the lowest $P$-values from the simple regression analysis and eliminated at level of $P>0.05$. Thus, confounding could be observed as each variable was included and tested by running the model with and without that variable. Clustering by herd as a random effect was included in all models. Two-way interactions among all predictors were evaluated. Standardized residuals, leverage values, and delta betas were also examined (Dohoo et al., 2009). To include assessor differences, the assessors were included as a random effect and excluded if no random effect was present in the analyses. The level of significance was set at $P \leq 0.05$. The general model for all herds was

$$
\operatorname{Logit}\left(\mathrm{Y}_{\mathrm{ij}}\right)=\beta_{0}+\beta_{1} \mathrm{x}_{1 \mathrm{ij}}+\ldots+\beta_{\mathrm{k}} \mathrm{x}_{\mathrm{kij}}+\mathrm{Z}_{\mathrm{herd}(\mathrm{i})},
$$

where $Y_{\mathrm{ij}}$ is the dependent variable; $\beta_{0}$ is the intercept, $\beta_{1} \mathrm{x}_{1 \mathrm{ij}}+\ldots+\beta_{\mathrm{k}} \mathrm{x}_{\mathrm{kij}}$ are fixed effects for ith herd and jth animal; $Z_{\text {herd(i) }}$ is random effect due to clustering at herd level; and $\beta_{1}$ to $\beta_{\mathrm{k}}$ are regression coefficients cor- 


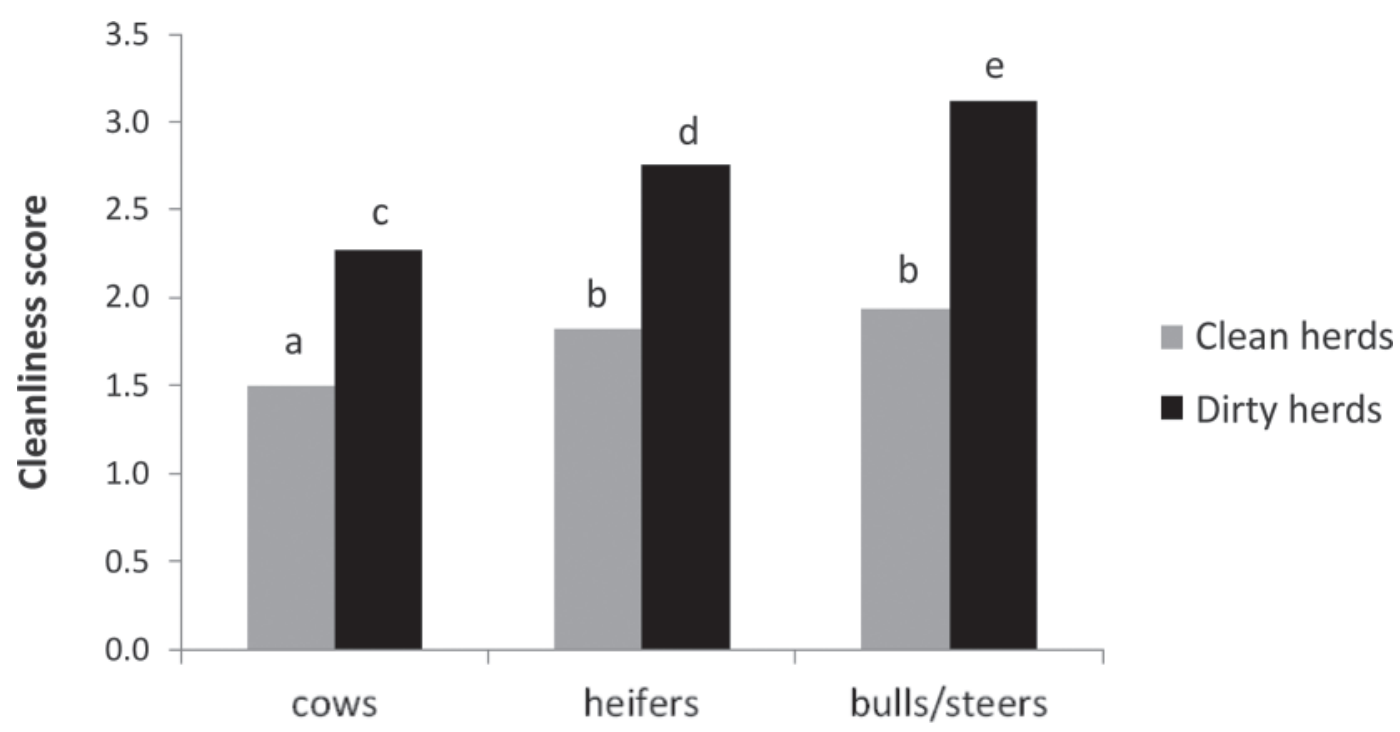

Figure 1. Means of animal cleanliness scores on a scale from 1 (clean) to 5 (very dirty) for animal types cows, heifers, and bulls/steers in the 2 categories of herds: clean herds (without dirty animals presented for slaughter in the previous 2 yr) and dirty herds (many dirty animals slaughtered the previous $2 \mathrm{yr}$ ). The means are different (ANOVA; $P<0.05$ ). Different letters indicate differences between means at the $P<$ 0.05 level by ANOVA.

responding to the independent explanatory variables $\mathrm{x}_{1}$ to $\mathrm{x}_{\mathrm{k}}$.

\section{RESULTS}

\section{Housing}

Of all the cows in the study, $30 \%$ were housed in 25 tiestall farms (11 clean herds and 14 dirty herds) and $70 \%$ were housed in 35 freestall farms (19 clean herds and 16 dirty herds). The heifers in this study were mostly kept in freestalls (63\%), whereas $11 \%$ were kept in tiestalls and $26 \%$ in pens with solid concrete or slatted floors without bedded lying areas. Fifty-eight percent of bulls/steers were housed in freestalls, of which $55 \%$ were on deep straw litter and $45 \%$ on sawdust, turf, mats, and other types of bedding, whereas $42 \%$ were kept in pens with solid or slatted floors without bedded lying areas.

\section{Herd and Milk Characteristics}

The mean herd size for all farms visited was 37 cowyears, ranging from 10 to 94 . These herds were larger than the average Norwegian herd size of 20 cow-years (NDHRS, 2011). The clean herds had a mean of 39 cow-years and the dirty herds had a mean of 35 cowyears. The herds had a mean of 19 heifers and 28 bulls/ steers. The proportions of types of animals in the study herds were $44 \%$ cows, $23 \%$ heifers, and $33 \%$ bulls/ steers. Almost all animals included in the study were of the Norwegian Red dairy breed, but some of the young stock was crossbreeds with beef cattle.

The mean milk yield within the 60 herds was 6,616 $\mathrm{kg}$ per cow-year; the clean herds had a mean of $6,933 \mathrm{~kg}$ and the dirty herds had a lower mean of $6,300 \mathrm{~kg}(P<$ $0.05)$. In the clean herds, the lowest yielding cows were cleaner (mean score of 1.08) than the high-yielding cows (1.69) using the 5 -point cleanliness scale $(P<0.05$ by Kruskal-Wallis test). In dirty herds, the trend was in the opposite direction, with the low-yielding cows assessed as being dirtier (2.62) than the high-yielding cows $(2.13 ; P<0.05)$. The mean SCC in milk for the 60 herds was 188,000 cells $/ \mathrm{mL}$. The mean was 169,000 cells/mL for the clean herds and 206,000 cells/mL for the dirty herds $(P<0.001$ by Kruskal-Wallis test).

\section{Distribution of Animal Cleanliness}

The distribution of the cleanliness scores on the 5 -category scale from 1 (clean) to 5 (very dirty) was 45 , $18,19,7$, and $11 \%$, respectively. Dairy cows in tiestalls were cleaner than dairy cows in freestalls, with mean hygiene scores of 1.76 and 1.91 , respectively $(P<0.05$ by $t$-test).

Of the 4,991 animals assigned cleanliness scores, 37\% were judged as dirty on the dichotomous scale. In the 30 clean herds, $20 \%$ of the animals were assessed as dirty; in the dirty herds, $53 \%$ of the animals were assessed as dirty. The results from cleanliness score assessments showed that dairy cows were cleaner than heifers and bulls/steers, and heifers were cleaner than males. All 


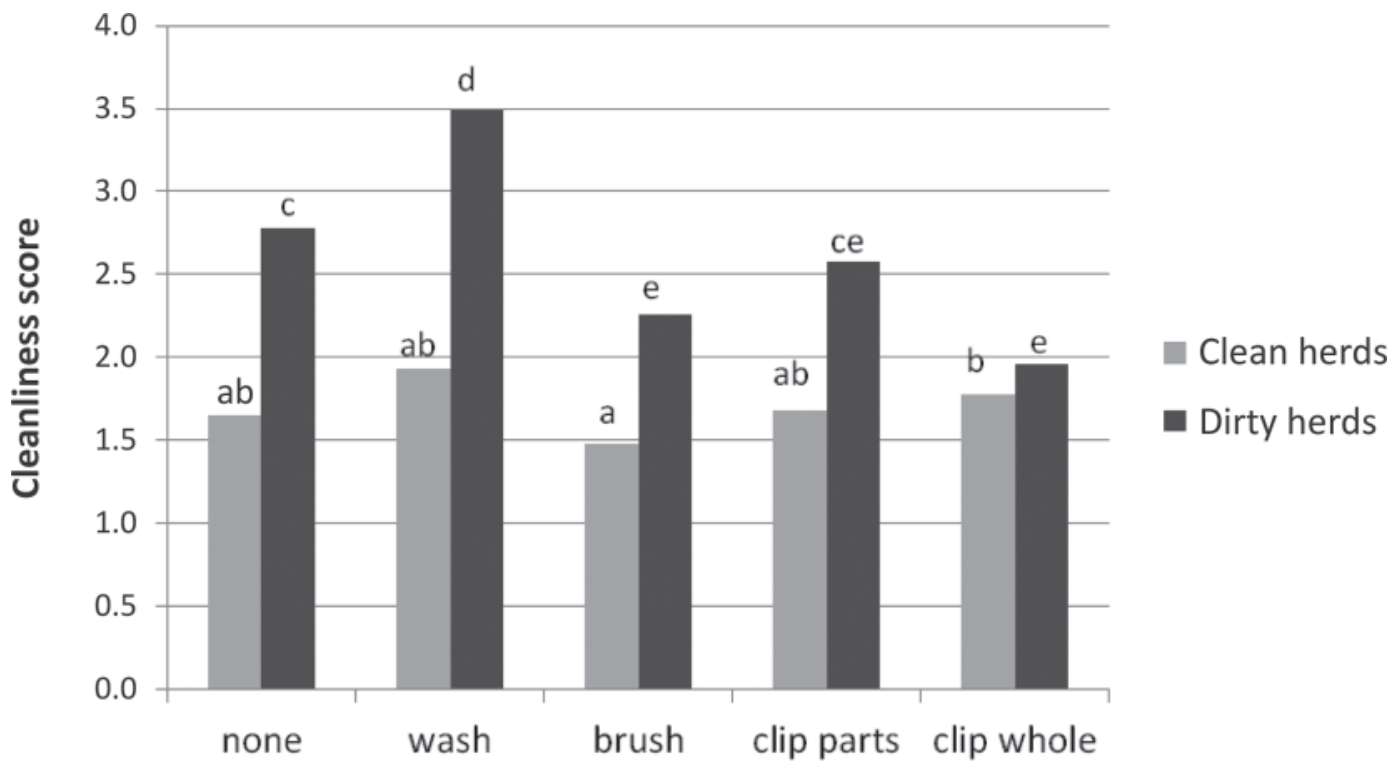

Figure 2. Means of animal cleanliness scores on a scale from 1 (clean) to 5 (very dirty) for different animal cleaning efforts (none, washing, brushing, clipping parts of hides, and clipping all hide) for cows, heifers, and bulls/steers. The gray bars indicate means in clean herds without dirty animals slaughtered in the previous $2 \mathrm{yr}$, and the black bars indicate means in dirty herds with many dirty animals slaughtered in the previous 2 yr. Different letters indicate differences between means at the $P<0.05$ level by ANOVA.

Table 2. Variables associated with dirty animals (animal cleanliness score) for $\mathrm{n}=60$ dairy herds with cows, heifers, and bulls ${ }^{1}$

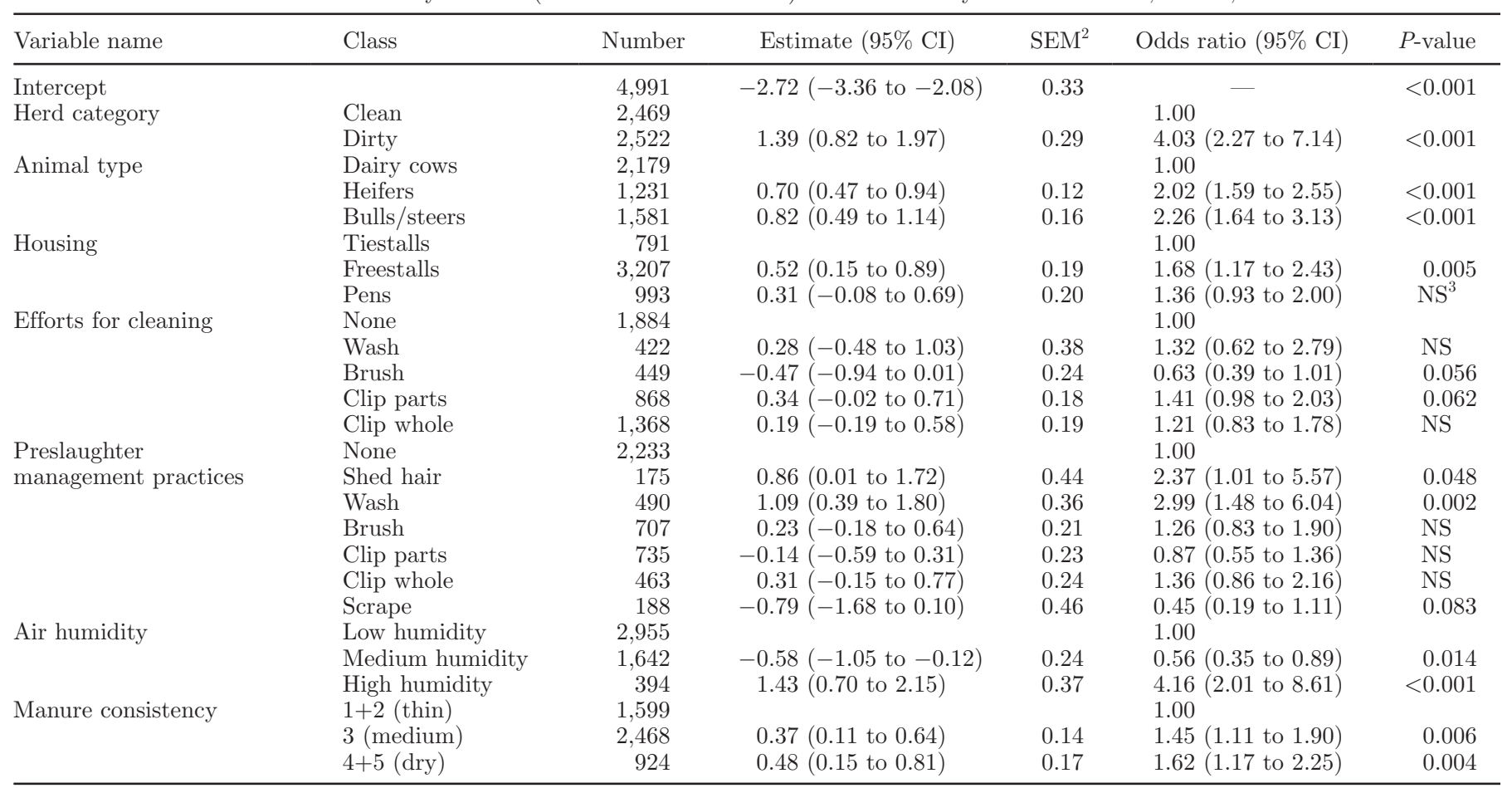

${ }^{1}$ Baseline (0-level) OR was set at 1.00 and compared with the other levels for categorical variables. All listed variables were significant for the model at $P<0.05$.

${ }^{2} \mathrm{SEM}$ for estimates.

${ }^{3} \mathrm{NS}=P>0.10$. 
animal types (cows, heifers, bulls/steers) were cleaner in the clean herds than in the dirty herds (Figure 1). The mean values of hygiene scores of cows, heifers, and bulls/steers in clean and dirty herds were 1.50, 1.82 , and 1.94 and $2.27,2.76$, and 3.12 , respectively. All means were different from each other $(P<0.05$ by ANOVA) except for heifers and bulls in clean herds.

We observed large differences between clean and dirty herds concerning management practices toward cleaning animals (Figure 2). In the clean herds, 97\% of the dairy cows were frequently clipped, washed, or brushed and, on the day of visit, $13 \%$ were judged as dirty by the assessor. In the dirty herds, $68 \%$ of the dairy cows were frequently clipped, washed, or brushed, and $30 \%$ of those were judged as dirty by the assessor (53\% of the cows not clipped and brushed were also dirty). For dairy cows, the means of cleanliness scores on a 5-category scale, where 1 was clean and 5 was dirty, for different cleaning efforts were (mean \pm stan- dard error of mean) $2.58 \pm 0.08$ (no cleaning effort), $1.86 \pm 0.06$ (brushing), $1.78 \pm 0.05$ (clipping parts of the body), and $1.62 \pm 0.03$ (clipping the whole body).

\section{Management}

Farmers with clean herds were more likely to expend effort in cleaning the animals (73\%) than farmers in the dirty herds (51\%), especially regarding clipping (62\% in clean herds and $28 \%$ in dirty herds). Floor cleaning was more frequent (twice or more per day) in the clean herds than in the dirty herds (83 and 50\%, respectively).

\section{Factors Associated with Dirty Animals}

Seven variables were identified $(P<0.05)$ for the general model, which had a random clustering effect of farm (Table 2). The odds ratio (OR) for detect-

Table 3. Variables associated with the "dirty" herds $(\mathrm{n}=30)$ with dirty cattle presented for slaughter in 2007 and $2008^{1}$

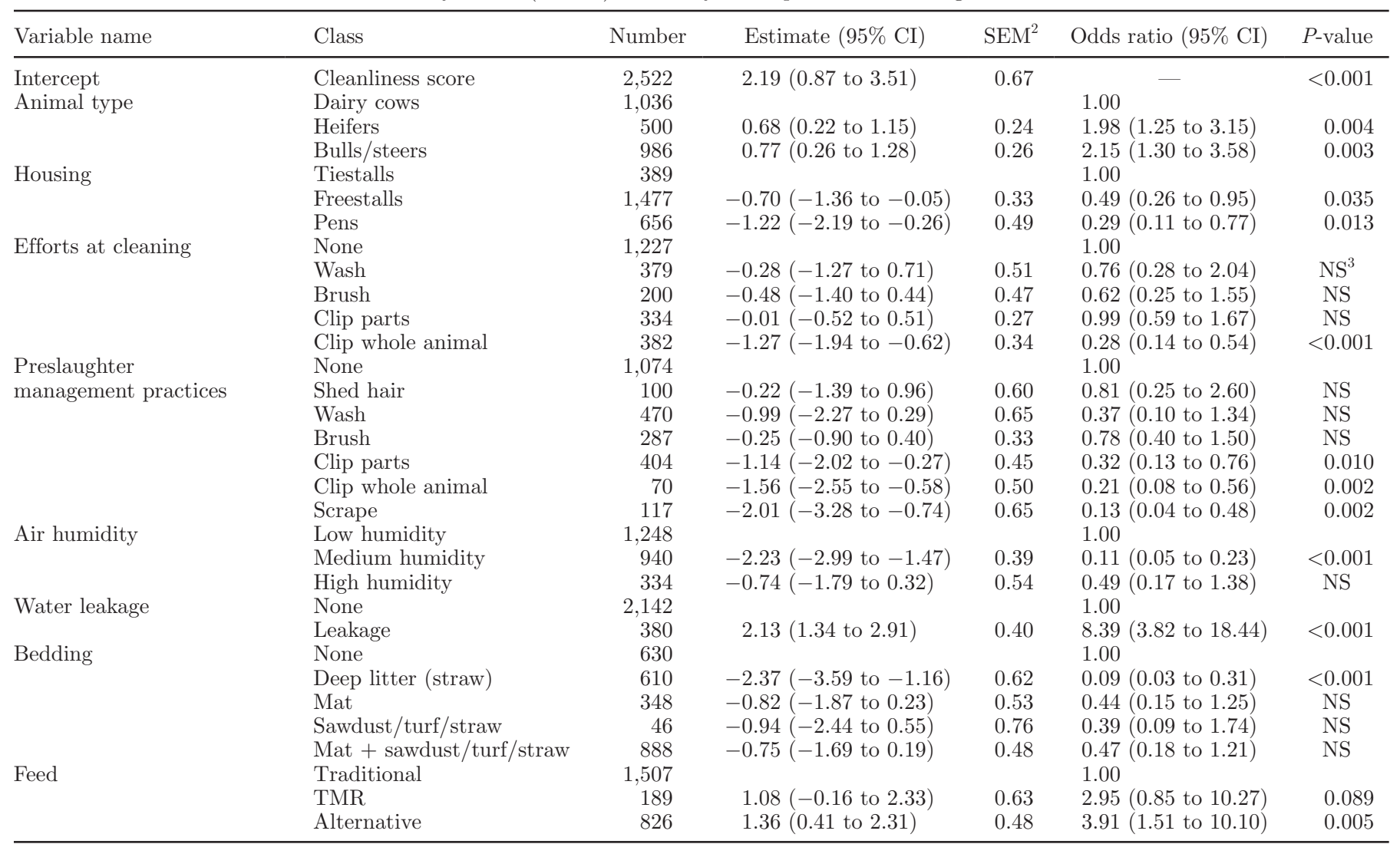

${ }^{1}$ Baseline (0-level) odds ratio was set at 1.00 and compared with the other levels for categorical variables. All listed variables were significant for the model at $P<0.05$. Dirty herds $(\mathrm{n}=30)$ were defined as those that had most deductions in payment registered due to dirty animals slaughtered in 2007 and 2008.

${ }^{2} \mathrm{SEM}$ for estimate.

${ }^{3} \mathrm{NS}=P>0.10$. 
Table 4. Variables associated with "clean" herds $(\mathrm{n}=30)$ without dirty cattle presented for slaughter in 2007 and 2008 "

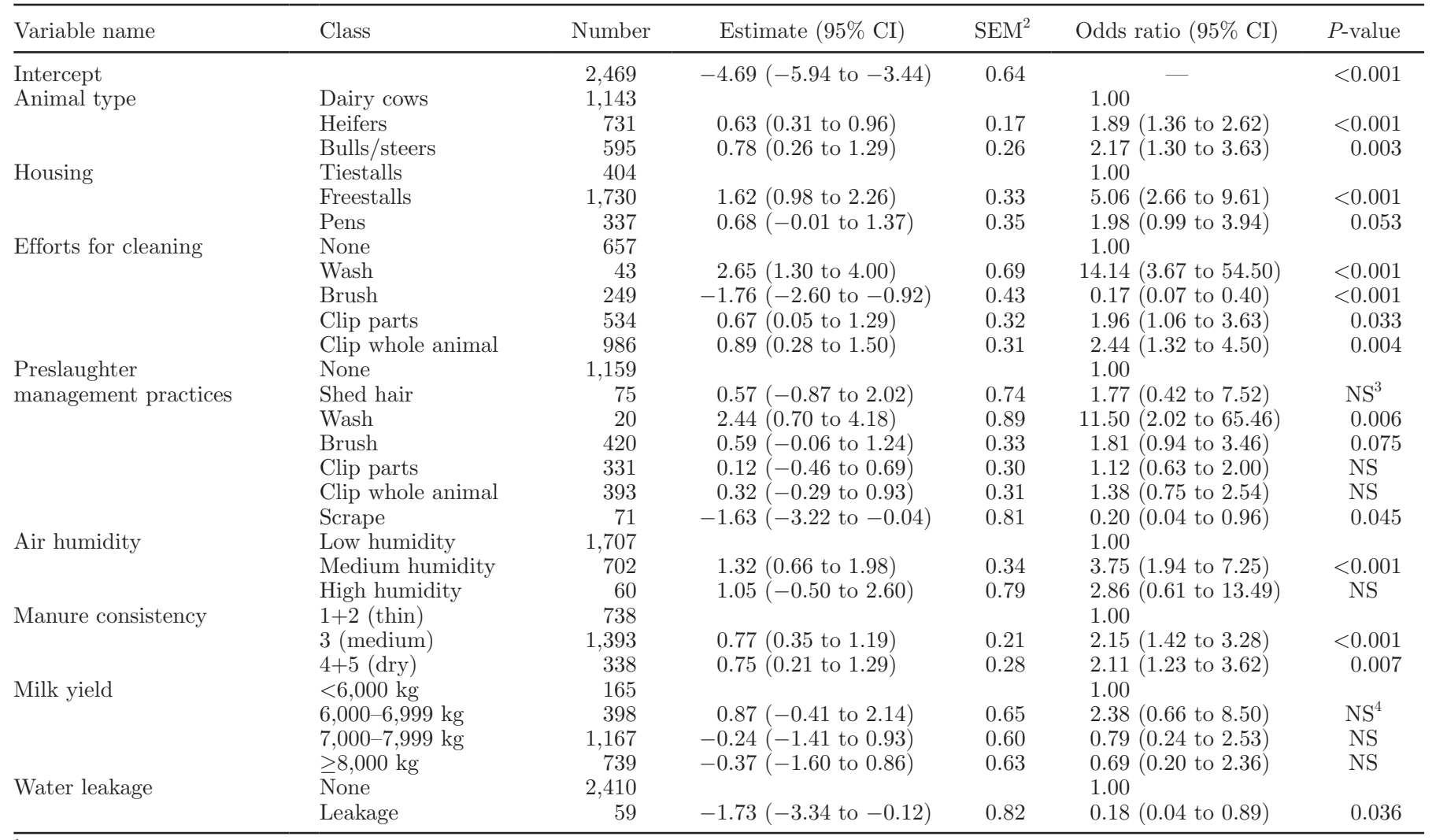

${ }^{1}$ Baseline (0-level) odds ratio was set at 1.00 and compared with the other levels for categorical variables. All listed variables were significant for the model at $P<0.05$. Clean herds $(\mathrm{n}=30)$ were those that had similar farm characteristics, but slaughtered only clean animals during 2007 and 2008, and thus had no deductions in payments registered.

${ }^{2} \mathrm{SEM}$ for estimate.

${ }^{3} \mathrm{NS}=P>0.10$.

${ }^{4}$ Milk yield had $P=0.034$, but the single levels had nonsignificant $P$-values.

ing dirtier animals in dirty herds compared with clean herds was 4.03. Bulls $(\mathrm{OR}=2.26)$ and heifers $(\mathrm{OR}=$ 2.02 ) were more often dirty compared with dairy cows. Compared with animals in tiestalls, those in free-stalls $(\mathrm{OR}=1.68)$ and pens $(\mathrm{OR}=1.36)$ had a higher odds of being dirty.

Factors associated with dirty animals for all 60 herds were (all with $P<0.05$ ), in ranked order, air humidity (medium and high air humidity compared with low), herds with dirty slaughter animals in 2007 and 2008 (dirty compared with clean herds), preslaughter management practices for cleaning animals (after shedding hair, washing, brushing, clipping parts, clipping the whole hide, and scraping compared with lack of preslaughter clean practices), type of animal (heifers and bulls/steers compared with cows), type of housing (freestalls and pens compared with tiestalls), manure consistency (medium and dry compared with thin and watery), and animal cleaning efforts (washing, brush- ing, clipping parts, and clipping the whole body compared with lack of animal cleaning efforts; Table 2).

\section{Risk Factors Identified in Dirty Herds}

For the dirty herds, with many dirty slaughter animals in the previous $2 \mathrm{yr}$, the factors associated with dirty animals were (all with $P<0.05$ ), in ranked order, drinking water leakage from nipples/troughs, type of feed (TMR and alternative feedstuffs compared with traditional rations), type of animals (heifers and bulls/ steers compared with cows), animal cleaning efforts and preslaughter management practices for cleaning animals (washing, brushing, clipping parts, and clipping the whole body compared with lack of animal cleaning effort), type of housing (freestalls and pens compared with tiestalls), air humidity (medium and high air humidity compared with low air humidity), and type of bedding (deep litter, mat, sawdust and 
mat plus sawdust compared with no bedding material; Table 3).

\section{Risk Factors Identified in Clean Herds}

Factors associated with dirty animals in clean herds were as follows (all $P<0.05$ ): efforts directed toward animal cleaning and preslaughter management practices for cleaning animals (washing, brushing, clipping parts, and clipping the whole body compared with lack of animal cleaning efforts), type of housing (freestalls and pens compared with tiestalls), indoor climate (medium and high air humidity compared with low air humidity), milk yield (higher milk yield levels compared with low yield, $<6,000 \mathrm{~kg}$ per cow-year), type of animal (heifers and bulls/steers compared with cows), manure consistency (medium and dry compared with thin and watery), and drinking water leakage from nipples/ troughs (Table 4).

\section{DISCUSSION}

This study showed a correlation between dirty cattle presented for slaughter and animal dirtiness on-farm. Dirty herds (those that had slaughtered many dirty animals in the previous $2 \mathrm{yr}$ ) had dirtier dairy cows, heifers, and bulls/steers on-farm compared with clean herds. The odds for an animal being dirty were 4 times greater in a dirty herd than in a clean herd.

Optimal feeding, superior housing design, good health status, and keeping the lying areas dry are regarded as essential foundations for keeping animals clean. In most herds, some animals do get dirty and need hide cleaning. In our study, the farms were visited at the time of the year when the animals were at their dirtiest. Even in clean herds, a large proportion of the animals was dirty (20\%). However, when animals from the clean herds were presented for slaughter in 2007 and 2008, they were considered clean. This means that animals become cleaner before being presented for slaughter, possibly because of cleaning efforts or due to natural events, such as shedding hair or after summer pasture. Our study showed that clean herds more frequently performed management practices directed toward cleaning the animals (73\%) than dirty herds (51\%). However, these cleaning practices were not always associated with reduced odds of dirty animals. In the models for clean herds and all 60 herds, a paradox emerged of odds being greater for detecting dirty animals on the day of visit, when cleaning efforts were performed than without any effort except for brushing the animals. Figure 2 indicates that one reason might be that animals in clean herds had an overall level of general cleanliness, and thus additional cleaning efforts were not needed.
This was probably because clean herds without animal cleaning efforts had more frequent floor cleaning than corresponding dirty herds with no cleaning efforts $(P<$ 0.05). Hence, the baseline herds (with which the other herds were compared) with no cleaning effort had different cleanliness levels for clean and dirty herds. In the clean herds with dirtiness problems, cleaning efforts might not have compensated for the dirtiness problem during the indoor feeding period (on the day of our visit), but might be more effective when performed preslaughter. On the other hand, in dirty herds, the findings were the opposite, with efforts for cleaning and preslaughter management practices resulting in lower odds for detecting dirty animals than in herds not using those efforts. The descriptive statistics (Figure 2), which do not account for other factors, also showed that animals in dirty herds without cleaning efforts were dirtier (higher cleanliness scores) than animals in herds using cleaning efforts.

Removal of long-term dung that has adhered to the hides of animals presented for slaughter is an effective means of avoiding deductions in carcass prices, but the removal is time-consuming and can cause pain and stress for both the animals and operator. The hides are often damaged by manure etching. Some farmers deliberately send their animals to slaughter at the times of year when the animals are cleaner; for example, after shedding hair or directly upon returning from summer pasture. However, several farmers have little or no focus on hide cleanliness. Hughes (2001) claimed that farmers handling the same cattle daily frequently fail to notice that the cows are becoming dirtier and develop "blindness" to the animals' condition. Awareness and motivation of the farmer appear to be important but were not assessed in this study, although these attitudes might be among the most critical factors.

In accordance with the findings of Hughes (2001), we found that air humidity was associated with cleanliness, with barns with low air humidity having cleaner animals. A good ventilation system, even in the very cold winter months, is necessary to avoid condensation dripping from the ceiling and high humidity, which result in both the bedding and the animals being damp (Hughes, 2001; Kirkland and Steen, 2001).

Other factors associated with dirty animals were type of animals and housing. In agreement with the opinions obtained from the advisors before the study, analyses showed that the dirtiest animals were bulls/ steers housed in pens, even when housing type was accounted for. A plausible explanation could be that farmers are reluctant to clip, brush, and wash bulls and steers, as they can be dangerous to approach in a pen. Some farmers invested in fixation or treatment boxes, in which animals can be treated individually. Feed 
barriers with headlocks were the most common fixation technique. This study showed that cattle in pens and freestall housing were generally dirtier compared with those in tiestalls. Freestall housing is becoming more common than tiestall housing in Norway. In 2006, $25 \%$ of the dairy cows in Norway had freestall housing (Simensen et al., 2007), and freestall housing will be compulsory in all dairy herds by 2024, according to Norwegian legislation (Norwegian Food Safety Authority, 2004). The results from the current study revealed many dirty animals in freestall herds and should be used to promote discussion about optimizing freestall design to improve animal cleanliness. Traditional, strenuous efforts such as manual muck scraping, clipping, washing, and brushing of cattle are important, but may be less relevant under conditions of expanding herd size and changes in farm management and production systems. A common problem in freestall housing is that some individual cattle (usually young heifers that have not settled in yet) demonstrate freestall refusal, and lie on the wet floor instead of the dry lying area. Risk factors are raising young heifers in slatted floor pens and positioning the freestall lying area against walls (Kjæstad and Myren, 2001a,b).

In dirty herds, type of feed use was associated with dirty animals. Alternative feedstuffs, such as potatoes, beets, whey, and chocolate, were more frequently used in dirty herds with manure consistency assessed as thin and were associated with higher odds of dirty animals. Similarly, Davies et al. (2000) found that cattle fed on "dry" (silage-based) diets with higher DM content were cleaner than cattle fed on "wet" (cereal-based) diets. Feed is closely linked to manure consistency. Ward et al. (2002) found that cows with firmer feces were cleaner than cows with thinner feces. We also found animals to be dirtier if they had a thin manure consistency, but this was the case only in the dirty herds. The opposite association was observed in the clean herds. However, the clean herds used more frequent floor cleaning and farmers used more effort in cleaning the animals with thin manure than the corresponding animals in the dirty herds. Thus, farmers with clean herds compensated for the negative effects of thin manure and were able to maintain the cleanliness of their animals.

Our study showed that dirty herds with cleanliness problems had lower milk yield and higher SCC compared with clean herds. The variable of SCC in milk, which reflects udder health, was borderline significant $(P=0.08)$ and excluded from the regression model for clean herds. Several studies have identified an association between cow cleanliness and milk quality as measured by SCC (Schreiner and Ruegg, 2003; Reneau et al., 2005). Elmoslemany et al. (2009) found that udder hair clipping reduced bacterial counts in bulk tank milk. As other studies have reported, bedding material is important for stall hygiene, animal hygiene (Herlin, 1997), and comfort (Tucker et al., 2003); we also found lower odds of dirty animals when farms used bedding material compared with concrete or slatted floors. Our study also showed that water leakage from drinking nipples/troughs into lying areas increased the odds of detecting dirty animals in the herds.

\section{CONCLUSIONS}

Our study confirmed the relationships between cleanliness of animals in dairy herds and factors associated with housing, feeding, and management. The factors associated with dirty animals identified in this study were high air humidity, many dirty slaughter animals in previous years, preslaughter management practices, animal type, housing, manure consistency, and efforts directed toward cleaning animals. Additional risk factors for the 2 groups, analyzed separately, were feed type, bedding, milk yield, and leakage of drinking water.

\section{ACKNOWLEDGMENTS}

We thank all 60 farmers participating in this study and are grateful to Lucy Robertson (Norwegian School of Veterinary Science, Oslo) for writing service. Funding was mainly provided by the Research Council of Norway and Foundation for Research Levy on Agricultural Products.

\section{REFERENCES}

Animalia. 2007. National guidelines for raw materials in Norwegian abattoirs (in Norwegian). Accessed Sept. 21, 2007. http://www. animalia.no/Tjenester/Bransjeretningslinjer/Hygienisk-ravarekvalitet/.

Animalia. 2011a. Dirty animals for slaughter (in Norwegian). Accessed March 2011. http://www.animalia.no/Artikler/2010/Skitne-slaktedyr---ingen-endring/.

Animalia. 2011b. Statistics from the Norwegian Carcass Register (in Norwegian). Accessed April 2011. http://www.animalia.no/Tjenester/Klassifisering/Statistikk-nokkeltall-for-slakt/Statistikk-Storfe-nokkeltall/.

Barbari, M., and P. Ferrari. 2006. Hygienic conditions of milking cows in loose housing systems with different lying areas. Pages 549-550 in Proc. World Congr. Commission Internationale du Genie Rural. VDI-Verl., Düsseldorf, Germany.

Breen, J. E., M. J. Green, and A. J. Bradley. 2009. Quarter and cow risk factors associated with the occurrence of clinical mastitis in dairy cows in the United Kingdom. J. Dairy Sci. 92:2551-2561.

Chiappini, U., P. Zappavigna, P. Rossi, and P. Ferrari. 1994. Straw flow litter for dairy cows: Experimental tests with different slopes and different quantities of straw. Page 138-144 in Proc. Dairy Systems for the 21st Century, Orlando, FL. Am. Soc. Agric. Eng., St. Joseph, MI.

Cook, N. B. 2002. The influence of barn design on dairy cow hygiene, lameness and udder health. Pages 97-103 in Proc. 35th Annu. Conf. Am. Assoc. Bovine. Pract., Stillwater, OK. Am. Assoc. Bovine. Pract., Auburn, AL. 
Davies, M. H., P. J. Hadley, P. J. Stosic, and S. D. Webster. 2000. Production factors that influence the hygienic condition of finished beef cattle. Vet. Rec. 146:179-183.

Doherty, A. M. 1999. Cattle cleanliness and its effect on carcass contamination. Hygiene Rev. 1999. Soc. Food Hyg. Technol. Accessed October 2003. http://www.sofht.co.uk/isfht/irish_99_cattle.htm.

Dohoo, I., W. Martin, and H. Stryhn. 2009. Veterinary Epidemiologic Research. 2nd ed. AVC Inc., Charlottetown, Prince Edward Island, Canada.

Elmoslemany, A. M., G. P. Keefe, I. R. Dohoo, and B. M. Jayaroa 2009. Risk factors for bacteriological quality of bulk tank milk in Prince Edward Island dairy herds. Part 1: Overall risk factors. J. Dairy Sci. 92:2634-2643.

Food Standards Agency. 2004. Clean beef cattle for slaughter: A guide for producers. Accessed October 2007. http://www.food.gov.uk/ multimedia/pdfs/publication/cleanbeefsaf1007.pdf.

Fregonesi, J. A., M. A. G. von Keyserlingk, C. B. Tucker, D. M. Veira, and D. M. Weary. 2009. Neck-rail position in the freestall affects standing behavior and udder and stall cleanliness. J. Dairy Sci. 92:1979-1985.

Herlin, A. H. 1997. Comparison of lying area surface for dairy cows by preference, hygiene and lying down behavior. Swed. J. Agric. Res. 27:189-196.

Hughes, J. 2001. A system for assessing cow cleanliness. In Pract. $23: 517-524$

Hulsen, J. 2005. Cow signals: A practical guide to dairy farm management. Rootbont Publishers, Zutphen, the Netherlands.

Kirkland, R. M., and R. W. Steen. 2001. Studies on the effects of housing system on the behaviour, welfare and performance of beef cattle and on factors affecting the cleanliness of housed cattle. Pages 30-39 in Agricultural Research Institute of Northern Ireland, 2000-2001. Agricultural Research Institute of Northern Ireland, Hillsborough, UK.

Kjæstad, H. P., and H. J. Myren. 2001a. Failure to use cubicles and concentrate dispenser by heifers after transfer from rearing facility to cubicle yard. Acta Vet. Scand. 42:171-180.

Kjæstad, H. P., and H. J. Myren. 2001b. Cubicle refusal in Norwegian dairy herds. Acta Vet. Scand. 42:181-187.

Lowman, B. G., B. Synge, and G. Caldow. 1997. Producing clean slaughter cattle. Technical Note T468. Scottish Agricultural College, Edinburgh, UK.

Nafstad, O. 1999. Injuries and quality defects in Norwegian cattle hides. Norsk Veterinær Tidsskrift 111:311-319. (in Norwegian)

European Union. 2004a. EC No 852: Corrigendum to Regulation EC/852/2004 of the European Parliament and of the Council of 29 April 2004 on the hygiene of foodstuffs. Off. J. L226:3-21.

European Union. 2004b. EC No 853: Corrigendum to Regulation EC/853/2004 of the European Parliament and of the Council of 29 April 2004 laying down specific hygiene rules for food of animal origin. Off. J. L226:22-82.
NDHRS (Norwegian Dairy Herd Recording System). 2011. Tine Norwegian Dairies: Nøkkeltall (key numbers). Accessed January 2011. http://medlem.tine.no/trm/tp/page?id=58\&key=9209.

Norwegian Food Safety Authority. 2004. New regulation concerning the keeping of cattle. Accessed December 2009. http://www.mattilsynet.no/aktuelt/nyhetsarkiv/dyrevelferd/ny_forskrift_om_ hold_av_storfe__9395.

NSCFS (Norwegian Scientific Committee for Food Safety). 2010. Panel on Biological Hazards: Decontamination of (domestic mammal) carcasses by the use of hot water or steam. Accessed April 2010. http://www.vkm.no/dav/ce5be76078.pdf.

Reneau, J. K., A. J. Seykora, and B. J. Heins. 2003. Relationship of cow hygiene scores and SCC. Pages 362-363 in Proc. Natl. Mast. Counc. Mtg. Natl. Mastitis Counc., Madison, WI.

Reneau, J. K., A. J. Seykora, B. J. Heins, M. I. Endres, R. J. Farnsworth, and R. F. Bey. 2005. Association between hygiene scores and somatic cell scores in dairy cattle. J. Am. Vet. Med. Assoc. 227:1297-1301.

Ridell, J., and H. Korkeala. 1993. Special treatment during slaughtering in Finland of cattle carrying an excessive load of dung-Meat hygienic aspects. Meat Sci. 35:223-228.

Ruud, L. E., K. E. Bøe, and O. Østerås. 2010a. Risk factors for dirty dairy cows in Norwegian freestall systems. J. Dairy Sci. 93:52165224 .

Ruud, L. E., C. Kielland, O. Østerås, and K. E. Bøe. 2010b. Free-stal cleanliness is affected by stall design. Livest. Sci. 135:265-273.

Schreiner, D. A., and P. L. Ruegg. 2003. Relationship between udder and leg hygiene scores and subclinical mastitis. J. Dairy Sci. $86: 3460-3465$.

Simensen, E., C. Kielland, K. Bøe, L. Ruud, and G. Næss. 2007. Production and health in relation with farming systems and housing in Norwegian free-stalls (in Norwegian). Pages 609-612 in Proc. Husdyrfors $\varnothing$ ksm $\varnothing$ tet, Lillestrøm, Norway.

Swedish Board of Agriculture. 1998. Standards for assessing fecal contaminated slaughter animals (in Swedish). http://www.jordbruksverket.se/download/18.595401461210ae2d589800032972/KCF-nor $\mathrm{m}+\mathrm{f} \% \mathrm{C} 3 \% \mathrm{~B} 6 \mathrm{r}+\mathrm{bed} \% \mathrm{C} 3 \% \mathrm{~B} 6 \mathrm{mning}+\mathrm{av}+\mathrm{g} \% \mathrm{C} 3 \% \mathrm{~B} 6 \mathrm{dself} \% \mathrm{C} 3 \% \mathrm{~B} 6$ rorenade+slaktdjur+2008.pdf

Tancouse, J. J. 1986. Skin, hide and leather defects. Leather Industries of America Laboratory, Cincinnati, $\mathrm{OH}$.

Tucker, C. B., D. M. Weary, and D. Fraser. 2003. Effects of three types of free-stall surfaces on preferences and stall usage by dairy cows. J. Dairy Sci. 86:521-529.

Ward, W. R., J. W. Hughes, W. B. Faull, P. J. Cripps, J. P. Sutherland, and J. E. Sutherst. 2002. Observational study of temperature, moisture, $\mathrm{pH}$ and bacteria in straw bedding, and faecal consistency, cleanliness and mastitis in cows in four dairy herds. Vet. Rec. 151:199-206. 